\title{
Evolution of Therapy Decision-Making Process for Advanced Non-Small Cell Lung Cancer
}

\author{
Vittorio Gebbia ${ }^{a}$ Gianfranco Mancuso $^{a}$ Lucia Lombardi ${ }^{b}$ Evaristo Maiello ${ }^{b}$ \\ a Department of Experimental Oncology and Medical Applications (DOSAC), University of Palermo, and \\ Medical Oncology Division, La Maddalena Clinic for Cancer, Palermo, and b'Medical Oncology Unit, Casa Sollievo \\ della Sofferenza, IRCSS, San Giovanni Rotondo, Italy
}

\section{Key Words}

Biological agents $\cdot$ Chemotherapy $\cdot$ Lung cancer ·

Histology $\cdot$ Pharmacogenomics

\begin{abstract}
Advanced non-small cell lung cancer remains a lethal disease with poor prognosis. In the last decades results of systemic chemotherapy have reached a disappointing plateau without significant differences between the most widely employed third-generation regimens. Recent scientific evidence has shed new light on the management of advanced non-small cell lung cancer, especially for the important role of histological definition in therapy-planning process. The results of new biologic agents are also reported as are the promising data on pharmacogenomic-guided treatment.
\end{abstract}

Copyright $\odot 2010$ S. Karger AG, Basel

\section{Introduction}

In the last decade the therapeutic panorama of advanced non-small cell lung cancer (NSCLC) has undergone major changes that appear to have led to better management of patients receiving first and subsequent lines of treatment [1]. We have moved from the therapeutic nihilism of the 1980s to the era of multiple lines of therapy [2].

To date, the systemic treatment of advanced NSCLC may achieve a $20-40 \%$ overall response rate to first-line chemotherapy, a median progression-free survival (PFS) of 4-7 months and a median survival of 10-12 months with a 1-year and a 2-year survival rate of 40 and $15 \%$, respectively [1]. Systemic therapy is also associated with symptom control and an improvement in patients' quality of life [3].

Growing scientific evidence has shown that NSCLC is not a single clinical entity but is rather composed of a heterogeneous group of diseases which differ in their biological and morphological characteristics [4]. Recent trials have demonstrated that clinical results of systemic chemotherapy may vary according to histological type, suggesting that treatment of squamous carcinomas should be different from that of non-squamous ones [5]. This difference has been further underlined by the clinical results achieved with new biologic agents such as the tyrosine kinase inhibitors and the anti-angiogenetic agents. Increasing scientific evidence from pharmacogenomic studies suggests that selection of active drugs according to the biomolecular characteristics of neoplasms

\section{KARGER \\ Fax +4161306 1234 E-Mail karger@karger.ch} www.karger.com

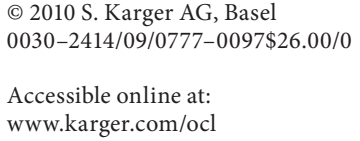


may improve the results of medical treatments [6]. Therefore, the therapy decision-making process has become more complex and may be guided by histological and biological as well as clinical data in order to optimize treatment for advanced NSCLC.

\section{Which Is the Best Front-Line Chemotherapeutic Treatment?}

Most of the larger trials published suggest equivalent activity for the newer cisplatin-based doublets including any of the third-generation drugs, i.e. gemcitabine, vinorelbine, paclitaxel and docetaxel, being the treatment choice based on toxicological and convenience data [7]. The results of another meta-analysis including 45 trials (11,867 patients) have recently provided evidence that modern third-generation regimens have comparable activity in the first-line treatment of advanced NSCLC, but produce significantly different rates of disease control [8]. The odds of obtaining an objective response to treatment were similar across different regimens. However, gemcitabine-based chemotherapy was associated with a $14 \%$ lower risk for immediate progression, whereas patients receiving paclitaxel showed a $22 \%$ higher risk for having $\mathrm{PD}$ as the best response. Docetaxel treatment provided a non-significant $9 \%$ lower odds for progression.

In the last decades many oncologists substituted carboplatin for cisplatin since the former drug is more easily administered on an outpatient basis and has a very low rate of renal and neurological toxicity [9]. However, the use of carboplatin has represented one of the major open questions concerning the optimal management of patients with advanced NSCLC. Although several metaanalyses have been published in the last two decades, the point has been clarified only very recently [10]. In fact an exhaustive meta-analysis based on individual patient data has been recently published showing an overall slight advantage for cisplatin-based combination. However, when the third-generation regimens are analyzed the difference in favor of cisplatin becomes wider, reaching statistical significance.

Today, these results must be re-interpreted in the light of new data recently published on the activity and tolerability of pemetrexed-based regimens as compared to a standard gemcitabine/cisplatin doublet [5]. A large noninferiority prospective trial showed that there were significantly more grade 3 and 4 granulocytopenia, thrombocytopenia, anemia, alopecia and increased febrile neutropenia associated with the gemcitabine arm, while emesis was comparable in the two arms. The most interesting data emerging from this trial are represented by the relationship that histology had in predicting improved survival.

\section{A New Role for Histology}

Another major breakthrough is represented by the role of histology. Sound scientific data have recently shown that squamous carcinomas should receive a different treatment from non-squamous NSCLC [4].

A large non-inferiority, phase III, randomized study has recently compared cisplatin $75 \mathrm{mg} / \mathrm{m}^{2}$ on day 1 and gemcitabine $1,250 \mathrm{mg} / \mathrm{m}^{2}$ on days 1 and 8 to cisplatin 75 $\mathrm{mg} / \mathrm{m}^{2}$ and pemetrexed $500 \mathrm{mg} / \mathrm{m}^{2}$ on day 1 every 3 weeks in a series of 1,725 chemotherapy-naïve ECOG 0 or 1 patients [11]. Results in terms of overall survival were non-inferior for cisplatin/pemetrexed as compared to cisplatin/gemcitabine in the average patient, with median survival being 10.3 months in both arms (HR 0.94) (fig. 1). Overall survival rates at 1 year and 2 years were 43.5 and $18.9 \%$ for cisplatin/pemetrexed, and 41.9 and $14.0 \%$ for cisplatin/gemcitabine, respectively. Response rates did not differ between the two regimens: $30.6 \%$ in the pemetrexed arm and $28.2 \%$ in the gemcitabine arm. Patients were not randomly assigned according to histology, but it was a pre-specified subset analysis. However, results are different if analyzed according to morphological subgroups, with overall survival statistically better for cisplatin/pemetrexed versus cisplatin/gemcitabine in the predefined group of patients with adenocarcinoma ( $\mathrm{n}=847,12.6$ vs.10.9 months, HR 0.64, $\mathrm{p}=0.03$ ) and large-cell carcinoma ( $\mathrm{n}=153,10.4$ vs. 6.7 months, HR $0.67, p=0.03$ ). On the other hand, patients with squamous cell histology showed a significant improvement in survival with cisplatin/gemcitabine as compared to cisplatin/pemetrexed ( $n=473,10.8$ vs. 9.4 months, HR 1.23 , $\mathrm{p}=0.05)$. Overall cisplatin/pemetrexed was better tolerated than cisplatin/gemcitabine since the rates of grade 3 or 4 hematological toxicity ( $<<0.001)$, febrile neutropenia $(\mathrm{p}<0.002)$ and alopecia $(\mathrm{p}<0.001)$ were statistically lower for pemetrexed. However, grade 3 or 4 nausea was less common in the gemcitabine arm $(\mathrm{p}<0.004)$. Some oncologists would require confirmative data before tailoring therapy according to histological morphology due to the fact that this trial was not aimed and powered to answer the question of superiority in adenocarcinoma; the majority of published studies of chemotherapy in NSCLC have not shown any significant difference 
Fig. 1. Phase III trial of pemetrexed/cisplatin (PC) versus gemcitabine/cisplatin (GC): overall survival according to histology. NOS = Not otherwise specified.

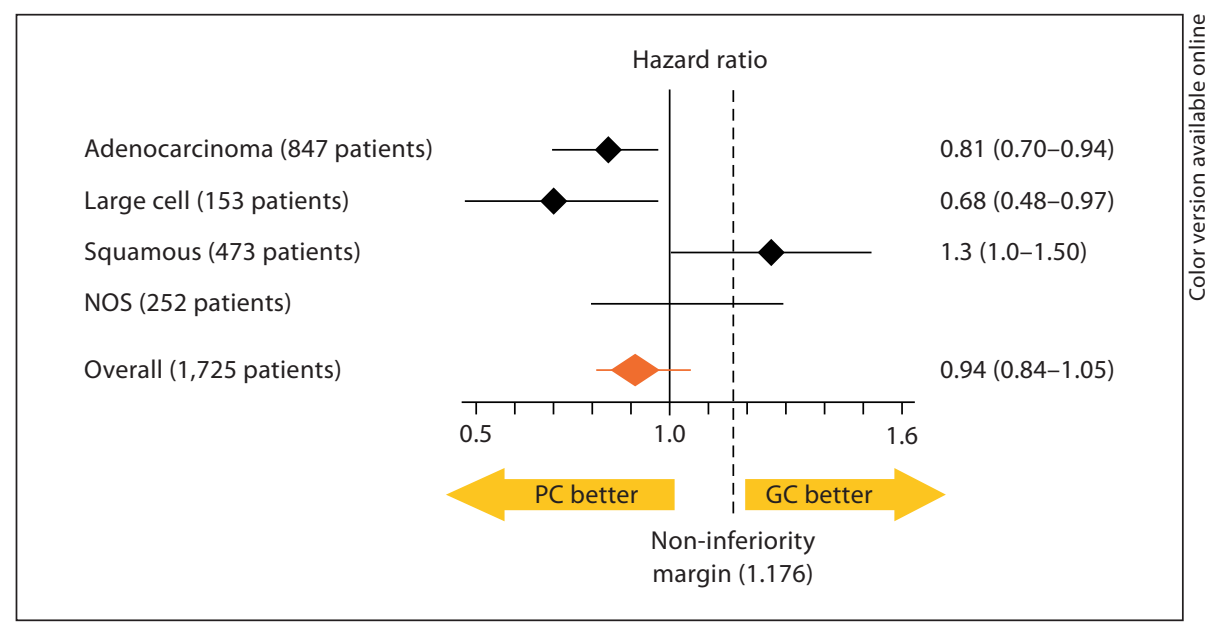

with respect to histology and these results may reflect the high expression of thymidylate synthase in squamous carcinoma, indicating resistance to pemetrexed [12]. However, data on histology are strongly supported by similar differential results in adenocarcinoma reported in a previously published phase III study which compared pemetrexed to docetaxel in the second-line setting [13]. This trial has also raised a second important issue concerning the relationship between smoking and survival. Current/former smokers had a significantly higher risk of death compared with never-smokers (HR 1.74, test for superiority $\mathrm{p}<0.001$ ) with a median survival of 15.6 months for never-smokers and 10.2 months for current or former smokers. The overall percentage of neversmoker patients was 14.8 and $14.1 \%$ for the pemetrexed and the gemcitabine arms, respectively.

\section{Optimal Duration of Front-Line Chemotherapy}

One of the major open questions in the management of advanced NSCLC is optimal duration of chemotherapy. ASCO clinical recommendations updated in 2003 suggested that chemotherapy should be withheld after 4 cycles in non-responding patients and continued up to a maximum of 6 cycles in responding ones [14]. In case bevacizumab or cetuximab were included in the front-line regimen, current scientific data suggest continuation of such biologic agents until progression [15-17]. In this setting, treatment interruptions often resolve treatment-related toxicity but the impact on clinical results is not known. Moreover, our knowledge of appropriate followup after stopping effective chemotherapy is insufficient.
A large meta-analysis including 13 randomized clinical trials (3,027 patients), none of which included biological agents, has recently addressed this issue [18]. The analysis showed that extending therapy, particularly with a third-generation agent or regimen, substantially improved PFS (HR 0.75, 95\% CI 0.69-0.81, p < 0.00001) but had a far less dramatic, but still statistically significant, effect on overall survival (HR 0.92, 95\% CI 0.86-0.99, $\mathrm{p}=0.03)$.

However, in clinical practice it should been kept in mind that this survival benefit is quite small. However, if additional trials will further support the survival benefit, especially with regard to severe side effects, chronic therapy may become a new therapeutic paradigm in the management of advanced NSCLC. This point of view has been very recently strengthened by a prospective study employing maintenance pemetrexed in non-progressing patients treated with gemcitabine/cisplatin. This phase III randomized trail on 663 patients showed that maintenance therapy with pemetrexed is well tolerated and offers superior overall survival (13.4 vs. 10.6 months, HR $0.79,95 \%$ CI $0.65-0.95, \mathrm{p}=0.012)$, PFS $(\mathrm{p}<0.00001)$ and objective response $(\mathrm{p}<0.001)$ compared with placebo after standard treatment with 4 cycles of a cisplatin-based combination in patients with no progressive disease [19]. The improvements in PFS (HR 0.47) and overall survival (HR 0.70) were observed primarily in patients with nonsquamous histology. Treatment by histology interaction for overall survival was significant $(p=0.038)$. Treatment-related grade 3 or 4 side effects were higher for pemetrexed ( 16 vs. $4 \%, \mathrm{p}<0.001)$, i.e. fatigue ( 5 vs. $0.5 \%)$ and neutropenia ( 2.9 vs. $0 \%$ ). There were no treatmentrelated fatalities. Fewer patients in the pemetrexed arm 
Table 1. Main trials on the use of bevacizumab in advanced NSCLC

\begin{tabular}{|c|c|c|c|c|c|c|c|}
\hline Study & $\begin{array}{l}\mathrm{Pa}- \\
\text { tients, } \mathrm{n}\end{array}$ & Schedule & RR\% & PFS & HR & OS & HR \\
\hline E4599 & 750 & $\begin{array}{l}\text { carboplatin } \\
\text { paclitaxel } \\
\text { carboplatin } \\
\text { paclitaxel } \\
\text { bevacizumab }\end{array}$ & $\begin{array}{l}15 \\
\text { vs. } \\
35^{*}\end{array}$ & $\begin{array}{l}4.5 \\
\text { vs. } \\
6.2^{*}\end{array}$ & 0.66 & $\begin{array}{l}10.3 \\
\text { vs. } \\
12.3^{*}\end{array}$ & 0.79 \\
\hline AVAiL & 657 & $\begin{array}{l}\text { cisplatin } \\
\text { gemcitabine } \\
\text { cisplatin } \\
\text { gemcitabine } \\
\text { bevacizumab }\end{array}$ & $\begin{array}{l}20 \\
\text { vs. } \\
34^{*}\end{array}$ & $\begin{array}{l}6.1 \\
\text { vs. } \\
6.7^{*}\end{array}$ & 0.75 & $\begin{array}{l}13.1 \\
\text { vs. } \\
13.6\end{array}$ & 0.93 \\
\hline
\end{tabular}

* Statistically significant. OS = Overall survival; $\mathrm{RR}=$ relative risk.

(51.5 vs. $67.1 \%, \mathrm{p}<0.001)$ received systemic post-discontinuation therapy. The optimal timing of second-line chemotherapy in non-progressing patients remains uncertain. This issue has been addressed in a recently published trial which explored the efficacy and safety of docetaxel administered either immediately after the end of front-line chemotherapy or at disease progression [20]. There was a statistically significant improvement in PFS and a non-statistically significant increase in overall survival when docetaxel was administered immediately after front-line gemcitabine/cisplatin without increasing toxicity or decreasing patients' quality of life.

\section{Anti-Angiogenetic Agents: New Criteria for Patient Selection}

Table 1 shows the results of the major studies reporting data on the use of bevacizumab in advanced NSCLC. The ECOG E4599 trial [15] reported a statistically significant advantage of bevacizumab ( $15 \mathrm{mg} / \mathrm{kg}$ ) plus standard carboplatin and paclitaxel over the chemotherapy doublet alone in terms of response rate ( $35 \mathrm{vs.} 15 \%, \mathrm{p}<0.001$ ), PFS (6.2 vs. 4.5 months, HR 0.66, $\mathrm{p}<0.001$ ) and overall survival (12.3 vs. 10.3 months, HR 0.79, $\mathrm{p}=0.003$ ). The AVAiL study employed bevacizumab plus the gemcitabine/cisplatin doublet that was considered the standard treatment for advanced NSCLC in Europe [16]. Despite bevacizumab administration being associated with a statistically higher overall response rate (34 vs. 20\%) and a longer PFS
(6.7 vs. 6.1 months), no advantage was reported in terms of overall survival. These results led to the approval of bevacizumab for advanced NSCLC. However, several criticisms have been raised concerning the use of bevacizumab in combination with carboplatin and paclitaxel, which is considered a standard treatment in the USA but not in Europe where only a minority of pulmonary oncologists employ this doublet. Moreover, the E4599 study reported a very low response rate, which is considered sub-optimal. Some concerns have also been raised concerning the AVAiL study since no impact on overall survival was achieved, and the difference in PFS - albeit statistically significant - is not felt clinically meaningful to justify the use of an expensive biologic treatment which may increase toxicity. Another important issue is represented by toxicity which has lead to the definition of strict inclusion and exclusion criteria [21]. Bevacizumab-based therapy should be restricted to fit patients with adenocarcinoma with no or little co-morbidity. This selection of patients should be guided by accurate evaluation of patient characteristics.

\section{Pharmacogenomics}

Preclinical and clinical experimental evidence has recently suggested that pharmacogenomics may guide the therapeutic management of advanced NSCLC potentially improving survival in some subpopulations of patients. The excision repair cross-complementation group 1 protein (ERCC1) is an enzyme which belongs to the DNA repair complex in which hyper-expression confers a high repair ability to cancer cells associated with in vitro resistance to cisplatin [6]. A prospective trial of tumor biology-driven chemotherapy (docetaxel/cisplatin doublet) in patients with advanced NSCLC unselected for histology has been carried out, showing a response rate of 51\% in patients whose treatment was guided by pharmacogenomic analysis and 39\% in patients who did not have a selective treatment [22]. These observations are supported by the report of lack of benefit in radically operated patients treated with adjuvant chemotherapy whose tumor had a high level of ERCC1 [23].

The ribonucleotide reductase M1 gene (RRM1) encodes the regulatory subunit of ribonucleotide reductase important in the synthesis of DNA, controlling a rate-limiting step. Gemcitabine inhibits this enzyme; therefore, a high level of RRM1 might be associated with relative resistance to gemcitabine combinations. A recent clinical study has reported an inverse relationship between RRM1 
expression and tumor shrinkage, strongly suggesting that tumor RRM1 expression is a major predictor of disease response to gemcitabine/platinum chemotherapy, conditioning improved survival for patients with low as opposed to high tumor RRM1 expression when treated with gemcitabine-containing chemotherapy [24].

Experimental evidence suggests that over expression of breast cancer susceptibility gene 1 (BRCA1) enhances sensitivity to apoptosis induced by anti-microtubule drugs such as docetaxel and vinorelbine and resistance to cisplatin [6]. The receptor-associated protein 80 (RAP80) and Abraxas are interacting proteins that form complexes with BRCA1 and could modulate the effect of BRCA1. In a recent controlled clinical trial the use of customized chemotherapy according to BRCA1 expression levels was associated with excellent median and 2-year survival for some subsets of NSCLC patients. Median survival exceeded 28 months for patients with epidermal growth factor receptor (EGFR) mutations, and was 11 months for patients with low BRCA1, 9 months for patients with intermediate BRCA1, and 11 months for patients with high BRCA1. Two-year survival was 73.3, 41.2, 15.6 and $0 \%$, respectively. Median survival was influenced by RAP80 expression in the three BRCA1 groups, and RAP80 could play a crucial modulating role in this model.

\section{Conclusions}

Despite the fact that new cisplatin-based chemotherapeutic doublets have reached a plateau in the last decade, new scientific evidence has highlighted the role of histology and biology in the optimization of advanced NSCLC treatment. Lung adenocarcinoma has received consider- able attention, not only because it has become the most frequent NSCLC in many countries but also because it has shown differential response to new agents such as pemetrexed, bevacizumab and EGFR tyrosine kinase inhibitors. The latter may be explained by the association of adenocarcinoma with activating EGFR mutations.

These data have increase the importance of a better histological analysis, which may be challenging for the pathologist if the biopsy specimen is not adequate. However, adequate histological specimens allow a precise morphological diagnosis in more than $80 \%$ of cases. Moreover, in many cases NOS (not otherwise specified) carcinomas may be better characterized by immunochemistry methods such as TTF-1, CK 7, napsin and p63.

Recent data have shown that the pemetrexed/cisplatin doublet is superior to gemcitabine/cisplatin in non-squamous cell carcinoma and the opposite is likely to be true in squamous cell carcinomas. Moreover, maintenance treatment in non-progressing patients may significantly improve results in terms of survival if tolerability is good. The addition of bevacizumab to cisplatin-based chemotherapy slightly improves response rates and time to progression, but the impact on overall survival in patients with adenocarcinoma is questionable. The addition of cetuximab to cisplatin/vinorelbine regimen in patients with positive immunochemistry for EGFR improves survival but the extent of this advantage is not necessarily clinically relevant.

\section{Disclosure Statement}

The authors declare that they have no financial conflict of interest.

\section{References}

1 NSCLC Meta-Analyses Collaborative Group: Chemotherapy in addition to supportive care improves survival in advanced non-small-cell lung cancer: a systematic review and meta-analysis of individual patient data from 16 randomized controlled trials. J Clin Oncol 2008;26:4617-4625.

2 Ramalingam S, Sandler AB: Salvage therapy for advanced non-small cell lung cancer: factors influencing treatment selection. Oncologist 2006;11:655-665.

-3 Plunkett TA, Chrystal KF, Harper PG. Quality of life and the treatment of advanced lung cancer. Clin Lung Cancer 2003;5:28-32.
4 Einhorn LH: First-line chemotherapy for non-small-cell lung cancer: is there a superior regimen based on histology? J Clin Oncol 2008;26:3485-3486.

-5 Scagliotti G, Hanna N, Fossella F, Sugarman K, Blatter J, Pterson P, Simms L, Sheperd FA: The differential efficacy of pemetrexed according to NSCLC histology: a review of two phase III studies. Oncologist 2009;14:253263.
-6 Rosell R, Perez-Roca L, Sanchez JJ, Cobo M, Moran T, Chaib I, Provencio M, Domine M, Sala MA, Jimenez U, Diz P, Barneto I, Macias JA, de Las Peñas R, Catot S, Isla D, Sanchez JM, Ibeas R, Lopez-Vivanco G, Oramas J, Mendez P, Reguart N, Blanco R, Taron M: Customized treatment in non-small-cell lung cancer based on EGFR mutations and BRCA1 mRNA expression. PLoS One 2009; 4:e5133.

7 Schiller JH, Harrington D, Belani CP, Langer C, Sandler A, Krook J, Zhu J, Johnson DH; for the Eastern Cooperative Oncology Group: Comparison of four chemotherapy regimens for advanced non-small-cell lung cancer. NEJM 2002;346:92-98. 
8 Grossi F, Aita M,b Deferrari C, Rossetti F, Brianti A, Fasola G, Vinant O, Pronzato P, Pappagallo G: Impact of third-generation drugs on the activity of first-line chemotherapy in advanced non-small cell lung cancer: a meta-analytical approach. Oncologist 2009;14:497-510.

9 Gebbia V, Oniga F, Agueli R, Paccagnella A: Treatment of advanced non-small cell lung cancer: chemotherapy with or without cisplatin? Ann Oncol 2006;17(suppl 2):ii83-ii87.

-10 Ardizzoni A, Boni L, Tiseo M, Fossella FV, Schiller JH, Paesmans M, Radosavljevic D, Paccagnella A, Zatloukal P, Mazzanti P, Bisset D, Rosell R; for the CISCA (CISplatin versus CArboplatin) Meta-analysis Group: Cisplatin- versus carboplatin-based chemotherapy in first-line treatment of advanced non-small-cell lung cancer: an individual patient data meta-analysis. J Natl Cancer Inst 2007;99:847-857.

-11 Scagliotti GV, Parikh P, von Pawel J, Biesma B, Vansteenkiste J, Manegold C, Serwatowski P, Gatzemeier U, Digumarti R, Zukin M, Lee JS, Mellemgaard A, Park K, Patil S, Rolski J, Goksel T, de Marinis F, Simms L, Sugarman KP, Gandara D: Phase III study comparing cisplatin plus gemcitabine with cisplatin plus pemetrexed in chemotherapy-naive patients with advanced-stage non-small-cell lung cancer. J Clin Oncol 2008;26:3543-3451.

$\checkmark 12$ Janku F, Bird B: Personalized medicine in advanced non-small-cell lung cancer: reality or wishful thinking? J Clin Oncol 2008;26: 5651.

-13 Hanna N, Shepherd FA, Fossella FV, Pereira JR, De Marinis F, von Pawel J, Gatzemeier U, Tsao TC, Pless M, Muller T, Lim HL, Desch C, Szondy K, Gervais R, Shaharyar, Manegold C, Paul S, Paoletti P, Einhorn L, Bunn PA Jr: Randomized phase III trial of pemetrexed versus docetaxel in patients with non-smallcell lung cancer previously treated with chemotherapy. J Clin Oncol 2004;22:1589-1597.
4 Pfister DG, Johnson DH, Azzoli GC, Sause W, Smith TJ, Baker S Jr, Olak J, Stover D, Strawn JR, Turrisi AT, Somerfield MR: American Society of Clinical Oncology treatment of unresectable non-small-cell lung cancer guideline: update 2003. J Clin Oncol 2004;22:330-353.

15 Sandler A, Gray R, Perry MC, Brahmer J, Schiller JH, Dowlati A, Lilienbaum R, Johnson DH: Paclitaxel-carboplatin alone or with bevacizumab for non-small-cell lung cancer N Engl J Med 2006;355:2542-2550.

16 Reck M, von Pawel J, Zatloukal P, Ramlau R, Gorbounova V, Hirsh V, Leighl N, Mezger J, Archer V, Moore N, Manegold C: Phase III trial of cisplatin plus gemcitabine with either placebo or bevacizumab as first-line therapy for non-squamous non-small-cell lung cancer: AVAiL. J Clin Oncol 2009;27:1227-1234.

-17 Pirker R, Pereira JR, Szczesna A, von Pawel J, Krzakowski M, Ramlau R, Vynnychenko I, Park K, Yu CT, Ganul V, Roh JK, Bajetta E, O’Byrne K, de Marinis F, Eberhardt W, Goddemeier T, Emig M, Gatzemeier U; FLEX Study Team: Cetuximab plus chemotherapy in patients with advanced non-small-cell lung cancer (FLEX): an open-label randomised phase III trial. Lancet 2009;373:1525-1531.

18 Soon YY, Stockler MR, Askie LM, Boyer MJ: Duration of chemotherapy for advanced non-small-cell lung cancer: a systematic review and meta-analysis of randomized trials. J Clin Oncol 2009;27:3277-3283.

19 Belani CP, Brodowicz T, Ciuleanu T, Kim JH, Krzakowski M, Laack M, Wu YP, Peterson P, Krejcy K, Zielin C: Maintenance pemetrexed (Pem) plus best supportive care (BSC) versus placebo (Plac) plus BSC: a randomized phase III study in advanced non-small cell lung cancer (NSCLC). J Clin Oncol 2009;27 (suppl):185.
20 Fidias PM, Dakhil SR, Lyss AP, Loesch DM, Waterhouse DM, Bromund JL, Chen R, Hristova-Kazmierski M, Treat J, Obasaju CK, Marciniak M, Gill J, Schiller JH. Phase III study of immediate compared with delayed docetaxel after front-line therapy with gemcitabine plus carboplatin in advanced nonsmall-cell lung cancer. J Clin Oncol 2009;27: 591-598.

-21 Sandler AB, Schiller JH, Gray R, Dimery I, Brahmer J, Samant M, Wang LI, Johnson $\mathrm{DH}$ : Retrospective evaluation of the clinical and radiographic risk factors associated with severe pulmonary hemorrhage in first-line advanced, unresectable non-small-cell lung cancer treated with Carboplatin and Paclitaxel plus bevacizumab. J Clin Oncol 2009; 27:1405-1412.

22 Cobo M, Isla D, Massuti B, Montes A, Sanchez JM, Provencio M, Viñolas N, Paz-Ares L, Lopez-Vivanco G, Muñoz MA, Felip E, Alberola V, Camps C, Domine M, Sanchez JJ, Sanchez-Ronco M, Danenberg K, Taron M, Gandara D, Rosell R: Customizing cisplatin based on quantitative excision repair crosscomplementing $1 \mathrm{mRNA}$ expression: a phase III trial in non-small-cell lung cancer. J Clin Oncol 2007;25:2747-2754.

23 Arriagada R, Bergman B, Dunant A, Le Chevalier T, Pignon JP, Vansteenkiste J; International Adjuvant Lung Cancer Trial Collaborative Group: Cisplatin-based adjuvant chemotherapy in patients with completely resected non-small-cell lung cancer. N Engl J Med 2004;350:351-360.

-24 Bepler G, Kusmartseva I, Sharma S, Gautam A, Cantor A, Sharma A, Simon G: RRM1 modulated in vitro and in vivo efficacy of gemcitabine and platinum in non-small-cell lung cancer. J Clin Oncol 2006;24:47314737. 